\title{
THE GUILD OF SAWGRASS-INHABITING ANTS IN THE FLORIDA KEYS*
}

\author{
By Blaine J. Cole \\ Department of Biology, \\ University of Utah, \\ Salt Lake City, UT 84112
}

\begin{abstract}
A guild is a group of species using similar resources in a similar manner (Root 1967). The guild of ants on which I report here uses, as nest sites, the hollow stems of sawgrass (Cladium jamaicense). The primary objectives of this study were to examine this guild for the purposes of: 1 . ascertaining the extent to which there is evidence of competition for nest sites. 2. determining the extent to which available nest sites are filled. 3. determining whether Solenopsis picta (Emery) nests in association with other species.
\end{abstract}

\section{Materials and Methods}

I examined 119 dead, erect culms of sawgrass, Cladium jamaicense, on Sugarloaf Key in Monroe County, Florida. Data were collected between $7 / 29 / 81$ and $8 / 3 / 81$. Each stem had seven or more internodal regions. For the ants in sawgrass stems the following data were recorded: the species present, the inside diameter of the internodal segments occupied and the internodal segment in which the colony was housed. For Pseudomyrmex pallida (F. Smith) the number and location of queens were also recorded. The inside diameter of a culm was measured with a micrometer to the nearest $0.1 \mathrm{~mm}$. The internodal segments were numbered with the lowest segment numbered one. The numbered segments indicated relative height on the culm. Due to individual variation in the height of $C$. jamaicense, this does not translate directly into absolute height.

\section{Results}

Out of 119 sawgrass culms examined, 34 (29\%) did not have a colony of any species. The occurrences of various species as well as

*Manuscript received by' the editor September 10, 1982 
their co-occurrences with other species is given in Table 1. Pseudomyrmex pallida is by far the most frequent ant, found in 57 culms or $48 \%$ of the total. Tapinoma littorale (Wheeler) and Solenopsis picta are each found in approximately $10 \%$ of the total.

The co-occurrence of series are also given in Table 1. Solenopsis picta is found frequently with other species including $P$. pallida, Zacryptocerus varians (F. Smith), and Camponotus planatus (Roger). No other ant species co-occur with P. pallida. T. littorale is the only species frequent enough to examine statistically. If $P$. pallida and $T$. littorale assorted into culms independently of one another, the expected number of co-occurrences would be 5.75. T. littorale never co-occurs with $P$. pallida, a difference that is statistically significant $\left(\mathrm{X}^{2}=11.0, \mathrm{p}<0.001\right)$.

It is possible to calculate the probability that $S$. picta should be the only species that co-occurs with $P$. pallida. This calculation can be done independently of our knowledge that $T$. littorale is negatively associated with $P$. pallida $(\mathrm{p}=0.002)$ or contingent on our knowledge of this relationship $(p=0.02)$. In either case, it is shown that if any species occurs with $P$. pallida it is likely to be $S$. picta. It is not possible to statistically demonstrate the stronger statement that $S$. picta is positively associated with $P$. pallida. Indeed, this seems not to be the case due to co-occurrence of S. picta and other species.

If one combines the data of $Z$. varians, C. planatus, Leptothorax allardycei (Mann) and Pseudomyrmex elongatus (Mayr), one can also demonstrate that this aggregate is negatively associated with $P$. pallida $\left(\mathrm{X}^{2}=12.0 \mathrm{p}<0.001\right)$. Due to the relative rarity of these species, one cannot test each species individually. This result must be considered tentative.

Table 2 gives some characteristics of the nests of the guild of sawgrass inhabiting ants. The average inside diameter and standard deviation of internodes occupied by $P$. pallida is calculated separately for that subset of the colonies that occupy a single internode and for that subset that occupy more than one internode. Nests of $P$. pallida that occupy a single internode have an inside diameter of $2.38 \mathrm{~mm}$. The inside diameter of internodes occupied by P. pallida that are found in two internodes are 2.45 and 2.03 for the lower and upper chamber respectively. The diameter of the single nest chamber does not differ from that of the lower nest chamber of a P. pallida colony that occupies two chambers $\left(t_{s}=0.53, p>0.5\right)$. 
Table 1. Co-occurrence of Sawgrass Ants.

\begin{tabular}{|c|c|c|c|c|c|c|c|}
\hline Species found: & $\begin{array}{c}\text { no } \\
\text { other } \\
\text { ant }\end{array}$ & P.p. & Co-OC & urring & with: & C.p. & Total \\
\hline Pseudomyrmex pallida & 52 & - & 0 & 5 & 0 & 0 & 57 \\
\hline Tapinomla littorale & 10 & 0 & - & 0 & 1 & 0 & 12 \\
\hline Solenopsis picta & 2 & 5 & 0 & - & 3 & 1 & 11 \\
\hline Zacryptocerus varians & 2 & 0 & 1 & 3 & - & 0 & 7 \\
\hline Camponotus plantus & 3 & 0 & 0 & 1 & 0 & - & 4 \\
\hline Leptothorax allardycei & 0 & 0 & 1 & 0 & 1 & 0 & 2 \\
\hline Pseudomyrmex elongatus & 1 & 0 & 0 & 0 & 0 & 0 & 1 \\
\hline Unidentified spider & 1 & 1 & 0 & 0 & 0 & 0 & 2 \\
\hline Nothing & - & - & - & - & - & - & 34 \\
\hline
\end{tabular}

Table 2. Nest Characteristics of Sawgrass Ants

\begin{tabular}{lrlcc}
\hline \multicolumn{1}{c}{ Species } & & \multicolumn{2}{c}{ Nest Characteristics } & \# internodes \\
& & $\begin{array}{c}\text { Inside Diameter } \\
\text { mean }(\mathrm{sdev}, \mathrm{n})\end{array}$ & $\begin{array}{c}\text { Internode } \\
\text { Occupied }\end{array}$ & $\begin{array}{c}\text { occupied/ } \\
\text { culm }\end{array}$ \\
\hline Pseudomyrmex pallida & $\begin{array}{r}\text { sgl. chamber } \\
\text { lower }\end{array}$ & $\begin{array}{l}2.38(.41,39) \\
2.45(.41,13)\end{array}$ & 3.7 & 1.4 \\
& dbl. chamber & & & \\
Solenopsis picta & upper & $2.03(.37,13)$ & 4.7 & \\
Tapinoma littorale & & $3.41(1.04,12)$ & 2.2 & 1.2 \\
Camponotus planatus & & $2.45(.63,15)$ & 4.3 & 1.15 \\
Zacryptocerus varians & & $4.73(.82,7)$ & 2.3 & - \\
& & $3.13(.61,8)$ & 3.6 & - \\
\hline
\end{tabular}

The average inside diameter is greatest for $C$. planatus (4.73), surprisingly large for $S$. picta, which is such a minute ant, and smallest for $P$. pallida (2.38, single chamber). The average diameter of internodes occupied by $P$. pallida and $T$. littorale does not differ significantly ( $\mathrm{t}$-test, $\mathrm{t}_{\mathrm{s}}=.70, \mathrm{p}>0.5$ ).

As shown in Table 2 the internode occupied by the nest parallels the results of internode diameter. Since larger internodes are lower 
on the culm, species that inhabit internodes with large diameter also inhabit low internodes.

The number of internodes occupied per culm is given in Table 2 for P. pallida, S. picta, and T. littorale. P. pallida has a tendency to occupy more internodes per culm (1.4) than does either $S$. picta (1.2) or T. littorale (1.15).

In most $P$. pallida nests a queen was located. However, in $19 \%$ of the nests a queen was not seen. It is conceivable that the queen could have been overlooked in these nests. In the 46 nests in which a queen was noted, $31(67 \%)$ had a single queen, $8(17 \%)$ had two queens, 6 $(13 \%)$ and one had four queens. When multiple queens are found in nests occupying multiple chambers, there is no tendency for the queens either to be found in a single chamber or to disperse to separate chambers. When a single queen is found in a nest occupying multiple internodes there is a tendency for the queen to occupy the higher internode.

\section{Discussion}

The guild of sawgrass inhabiting ants is a collection of species for which there is evidence that certain pairs of species compete for nest sites and certain pairs of species do not. P. pallida and T. littorale are strongly negatively associated. This pair of species was not encountered inhabiting the same sawgrass culm. $P$. pallida and $T$. littorale occupy internodes of similar physical characteristics (inside diameter, and relative height on the culm). It is less likely that the two species compete for an internode of particular character than they compete for the space of an entire culm (Levings and Traniello 1981, Cole 1982).

$P$. pallida shows no evidence of competition for nest sites with $S$. picta. The distributions of S. picta and P. pallida are independent of one another. These two species are found in the same sawgrass culm with S. picta occupying larger and lower internodes. There is little evidence to suggest that $S$. picta is found in association with other species of ants. It seems to be found frequently in association with $P$. pallida simply due to the fact that $P$. pallida is common. S. picta has been referred to as a thief ant which nests in close proximity to other ants and specializes in stealing brood from them. In approximately half of the cases in which S. picta is found in a sawgrass culm 
with another species of ant, there is at least one intervening, empty internode between $S$. pict $a$ and the other species.

Of the total sawgrass culms, $71 \%$ are occupied by at least one species. Let $\mathrm{C}$ be the average probability that a species will colonize a sawgrass culm and $\mathrm{E}$ be the average probability that a colony will go extinct. Then the equilibrium fraction of sawgrass culms occupied is $\mathrm{C} / \mathrm{C}+\mathrm{E}=0.71$. One can then obtain an estimate of the rate of extinction relative to the rate of colonization as $\mathrm{C}=2.5 \mathrm{E}$.

If colonization takes place on an annual cycle, then one can estimate that the average lifespan of a colony which becomes established is about 2.5 years. This estimate assumes that the occupancy of sawgrass culms is at equilibrium. In addition, data from several species, each of which may not have the same demographic characteristics, are combined. This is not as bad as it seems, however, due to the fact that the bulk of the species' occurrences are of $P$. pallida. The estimate of average colony longevity is principally an estimate based on P. pallida.

The inside diameter and position of the lower nest chamber of $P$. pallida colonies that inhabit two internodes is comparable to the inside diameter and position of the internode occupied by $P$. pallida in a single nest chamber. This suggests that $P$. pallida move up to occupy a second internode. The fact that the queen of $P$. pallida tends to be found in the upper chamber suggests that the queen moves into the newer, smaller or higher nest chamber.

The average inside diameter of sawgrass culms occupied by $Z$. varians $(3.13 \mathrm{~mm})$ is not significantly different from the average inside diameter of hollow stems of red mangrove occupied by $Z$. varians $\left(2.95 \mathrm{~mm}\right.$, Cole $\left.1979, \mathrm{n}=114, \mathrm{t}_{\mathrm{s}}=0.94, \mathrm{p}>0.2\right)$. The major workers of $Z$. varians are morphologically modified for passive colony defense (Wilson 1976, Cole 1980). It is reasonable to suppose that there is selective pressure of $Z$. varians to choose, as nest sites, hollow stems that are of a suitable size to allow the major workers to block off the stem and bulldoze out intruders.

This research supported, in part, by a grant from Sigma Xi.

REFERENCES

COLE, B. J. 1979. Assembly of mangrove ant communities. Ph.D. dissertation. Princeton University. vi $+123 \mathrm{pp}$. 
CoLE, B. J. 1980. Repertoire convergence in two mangrove ants, Zacryptocerus varians and Camponotus (Colobopsis) sp. Insectes Sociaux 27: 265-275.

COLE, B. J. 1982. Assembly of mangrove ant communities: patterns of geographical distribution. J. of Anim. Ecol. (in press).

Levings, S. C. AND J. F. A. Traniello. 1981. Territoriality, nest dispersion and community structure in ants. Psyche 88: 265-319.

Root, R. B. 1967. The niche exploitation pattern of the blue-gray gnatcatcher. Ecol. Monogr. 37: 317-350.

Wilson, E. O. 1976. A social ethogram of the neotropical arboreal ant, Zacryptocerus varians (Fr. Smith) Anim. Behav. 24: 354-363. 

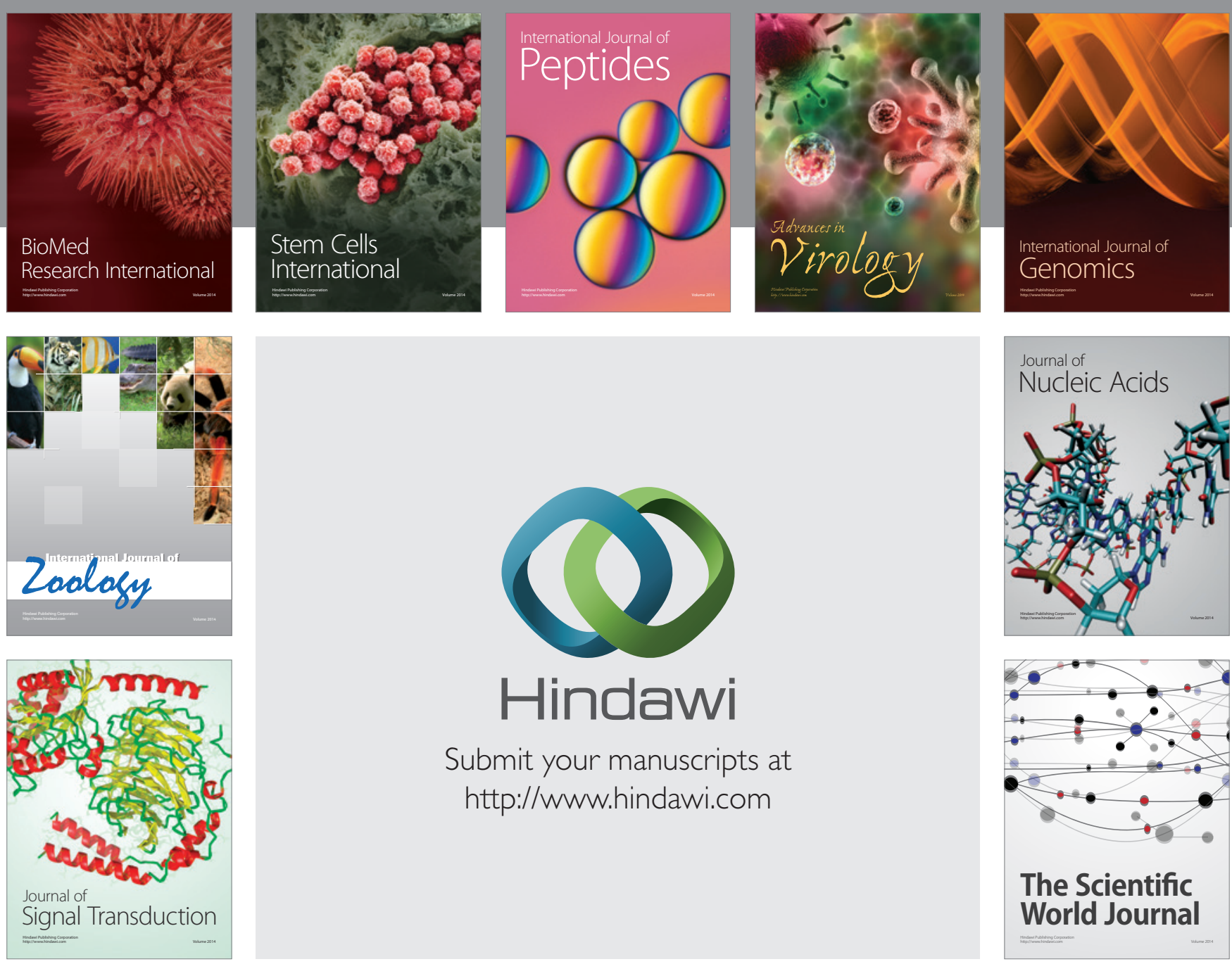

Submit your manuscripts at

http://www.hindawi.com
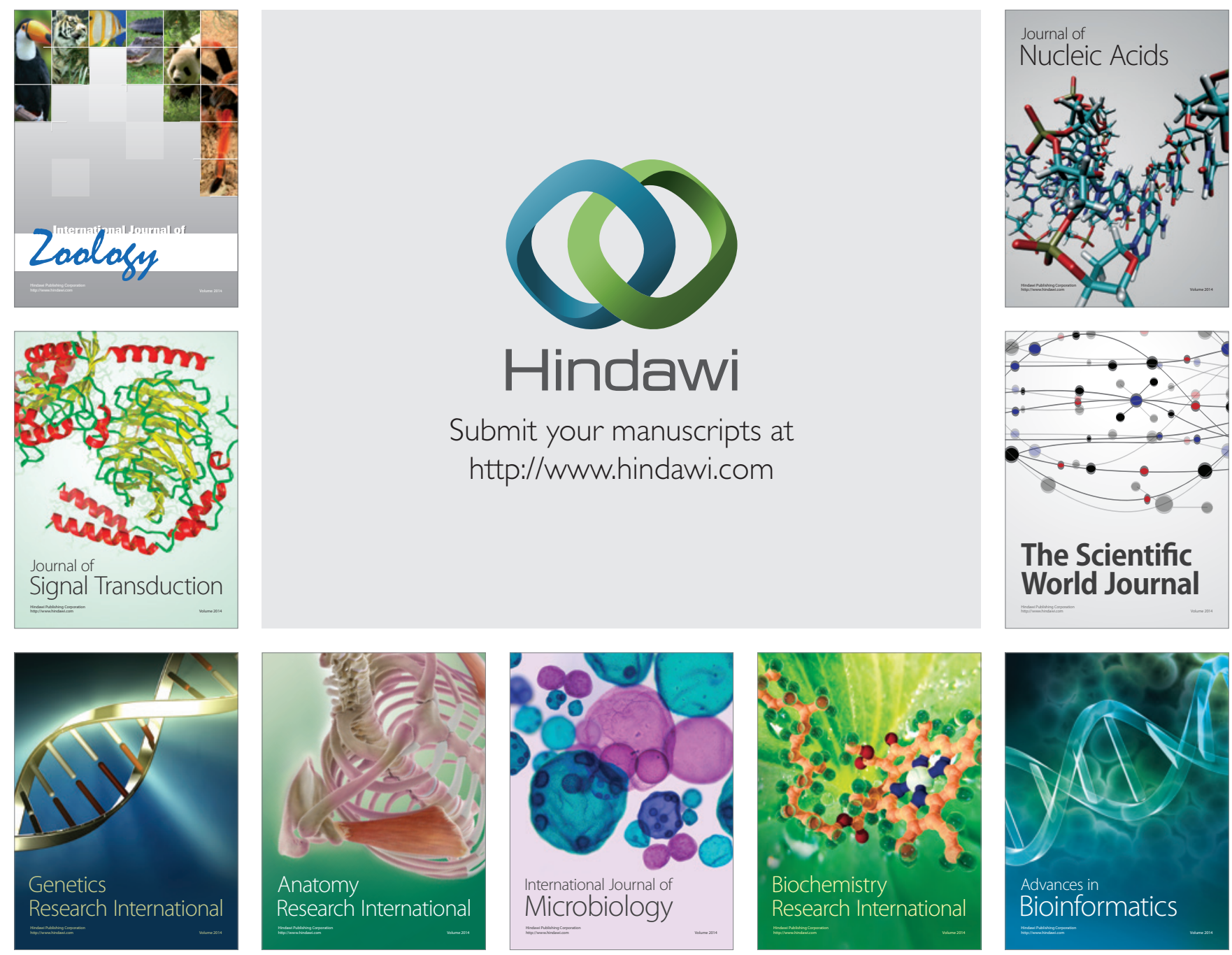

The Scientific World Journal
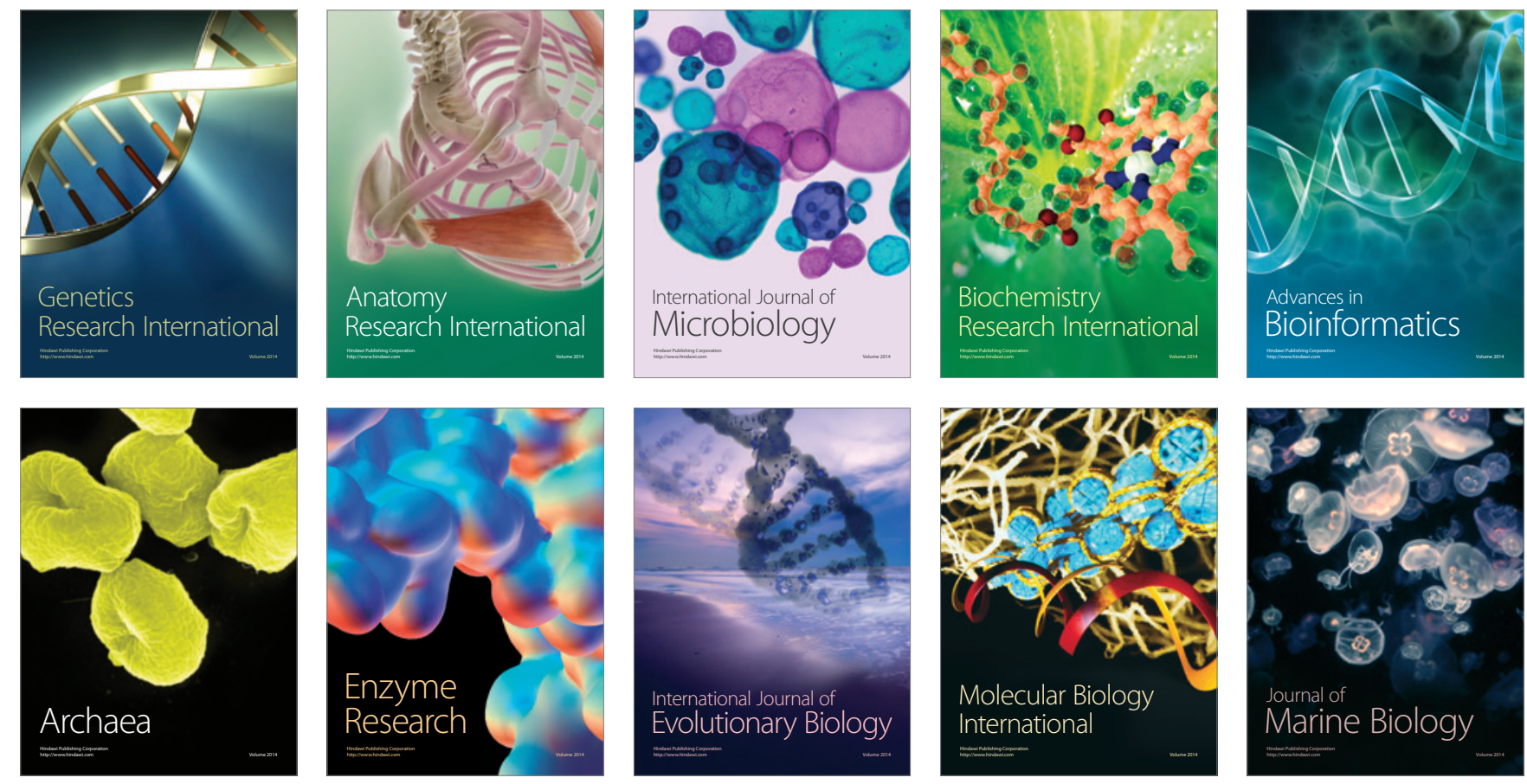